$06.4 ; 03.5$

\title{
Влияние фазовых превращений на взаимодействие алюминиевых сплавов при скоростях более $9 \mathrm{~km} / \mathrm{s}$
}

\author{
() Б.В. Румянцев ${ }^{1}$, И.В. Гук ${ }^{2}$, А.И. Козачук ${ }^{1}$, А.И. Михайлин ${ }^{2}$, С.И. Павлов ${ }^{1}$, М.В. Сильников ${ }^{2}$ \\ ${ }^{1}$ Физико-технический институт им. А.Ф. Иоффе РАН, Санкт-Петербург, Россия \\ 2 ЗАО „НПО „Спецматериалы“, Санкт-Петербург, Россия \\ E-mail: brum@mail.ioffe.ru
}

Поступило в Редакцию 4 февраля 2020 г.

В окончательной редакции 4 февраля 2020 г.

Принято к публикации 10 февраля 2020г.

\begin{abstract}
Исследуется внедрение алюминиевой струи со скоростью $8-11 \mathrm{~km} / \mathrm{s}$ в преграду из алюминиевых сплавов. Анализ кинетики и параметров проникания, поверхности каверны после внедрения позволяет утверждать, что при скоростях более $9 \mathrm{~km} / \mathrm{s}$ гидродинамический характер внедрения нарушается из-за плавления взаимодействующих металлов. Результаты исследования предназначены для разработки экранной защиты космических аппаратов от наиболее опасных фрагментов космического мусора.
\end{abstract}

Ключевые слова: высокоскоростной удар, плавление, испарение, техногенный мусор.

DOI: 10.21883/PJTF.2020.09.49368.18229

Классическая форма изменения баллистического предела, определенная при взаимодействии компактного ударника и экрана из алюминиевых сплавов, оставляет открытым вопрос о влиянии фазовых превращений на эффективность экранной защиты космических аппаратов $[1,2]$. В настоящей работе рассматривается действие удлиненного алюминиевого ударника по нормали к защите из алюминиевых сплавов при скоростях $8-11 \mathrm{~km} / \mathrm{s}$. Такие условия являются наиболее жесткими для экранной защиты космических аппаратов.

В качестве аналога удлиненного ударника в лабораторных условиях принята кумулятивная струя (КС), сформированная при схлопывании металлического конуса под действием продуктов детонации взрывчатых веществ $[3,4]$.

На рис. 1 приведена схема эксперимента по формированию КС при схлопывании конуса 1 из сплава АМГЗ диаметром $20 \mathrm{~mm}$ в основании под действием продуктов детонации заряда взрывчатого вещества массой $40 \mathrm{~g}$. После прохождения фокусного расстояния $60 \mathrm{~mm}$ КС внедрялась в преграду 2 из пластин алюминиевого сплава АМГб. Эксперименты проводились в вакуумной взрывной камере при давлении воздуха менее $2 \mathrm{kPa}$. По замыканию контактных датчиков 3 регистрировались времена $t$ проникания КС на глубину $L$ в преграду (символы на диаграмме $L(t)$, рис. 1 и 2). По остаточной каверне в преграде измерялись объем $v_{c a v}$ и конечная глубина внедрения $L_{e}$. Сплошные кривые на рис. 1 и 2 отражают результаты расчета в гидродинамическом приближении $[5,6]$ : траекторий формирования и проникания КС в преграду. Поскольку КС, получаемая при схлопывании воронки, имела градиент по скорости, приведено семейство траекторий движения частей струи от начальной скорости $V_{j 0}$ и ниже через равные промежутки значения скорости (прямые тонкие линии). Штриховой кривой представлены результаты численного моделирования с использованием осесимметричного эйлерова подхода [7] формирования и внедрения струй из воронок с углами 45 и $20^{\circ}$. На рис. 1,2 приведено сравнение расчетов и траекторий внедрения алюминиевых струй, сформированных схлопыванием воронок с углами при вершине $A$, равными $60,45,30$ и $20^{\circ}$, в преграду из дюраля АМГб.

В таблице приведены данные внедрения алюминиевой струи в преграду из АМГб.

Согласно модельным уравнениям состояния при высоких давлениях одномерного ударного сжатия $[9,10]$, плавление алюминия при ударном сжатии начинается при давлении $130 \mathrm{GPa}$ и свыше $180 \mathrm{GPa}$ алюминий на ударной адиабате находится в жидком состоянии. При адиабатической разгрузке из состояний на ударной адиабате больше $220 \mathrm{GPa}$ часть алюминия находится в парообразном состоянии.

Из сопоставления данных таблицы и рис. 2 видно, что отрезок струи со скоростью более $9 \mathrm{~km} / \mathrm{s}$ формирует каверну глубиной до $35 \mathrm{~mm}$ и в зоне внедрения часть алюминия находится в „ожиженном“ состоянии. Экспериментальные результаты определения $L(t)$ совпадают с численным моделированием и расчетами в гидродинамическом приближении при скоростях элементов струи более $9 \mathrm{~km} / \mathrm{s}$. После $3-4 \mu \mathrm{s}$ внедрение элементов струи с меньшими скоростями демонстрирует дестабилизацию проникания КС от внутреннего возмущения [11] с задержкой по времени (стрелка на рис. 2) и дальнейшим кардинальным отклонением от результатов гидродинамических расчетов. Внедрение струй, образованных из конусов с углами 45 и $60^{\circ}$, со скоростями меньше $9 \mathrm{~km} / \mathrm{s}$ хорошо моделируется.

Для получения дополнительной информации о состоянии взаимодействующих материалов в работе ис- 


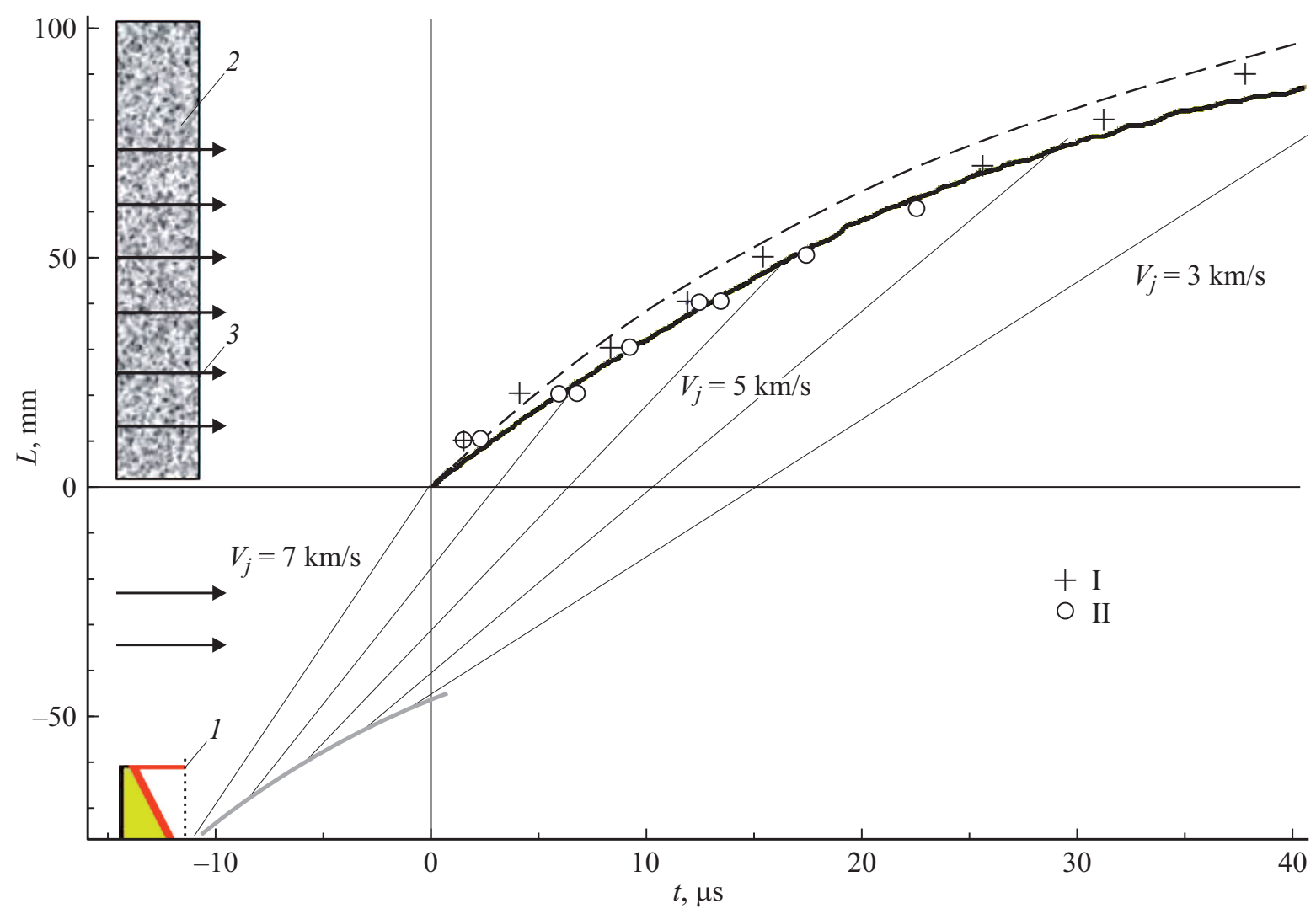

Рис. 1. Схема эксперимента. 1 - алюминиевая воронка, 2 - блок листов дюраля АМГ6, 3 - контактные датчики. Символы времена $t$ замыкания датчиков, расположенных на глубине $L$ в преграде для струй из воронок с углами 45 (I) и $60^{\circ}$ (II).

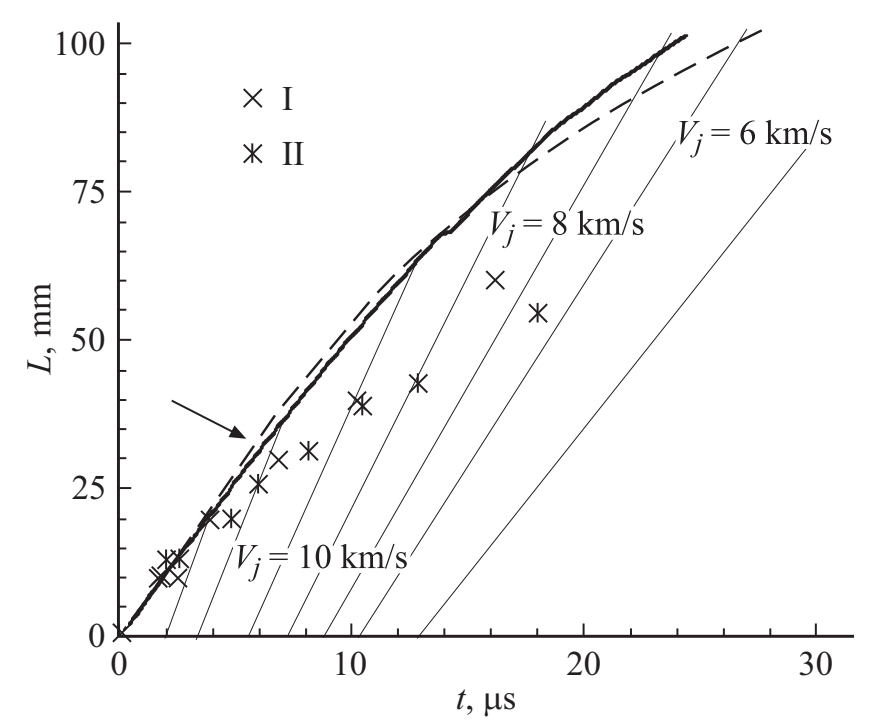

Рис. 2. Расчетные траектории и времена внедрения для струй, полученных при схлопывании воронок с углами 20 (I) и $30^{\circ}$ (II) в области преграды. Остальные обозначения те же, что на рис. 1.

следовалась поверхность каверны в начальной области внедрения. На рис. 3, $а$ приведены фотография поверхности каверны и для наглядности результат численного
Данные внедрения алюминиевой струи в преграду из АМГб

\begin{tabular}{c|c|c|c|c}
\hline$A,{ }^{\circ}$ & $\begin{array}{c}V_{j 0}, \\
\mathrm{~km} / \mathrm{s}\end{array}$ & $\begin{array}{c}L_{e}, \\
\mathrm{~cm}\end{array}$ & $\begin{array}{c}v_{\text {cav }}, \\
\mathrm{cm}^{3}\end{array}$ & $\begin{array}{l}P_{0 j}^{*}, \\
\mathrm{GPa}\end{array}$ \\
\hline 20 & 11.3 & 11.5 & 13.7 & 183 \\
30 & 10.0 & 10 & 9.0 & 157 \\
45 & 8.7 & 11 & 9.1 & 124 \\
60 & 7.6 & 9.5 & 8 & 102
\end{tabular}

${ }^{*} P_{0 j}$ - начальное давление внедрения, расчет по [8].

моделирования распределения давления в области внедрения. Анализировались SEM-изображения, полученные на растровом электронном микроскопе JSM 7001F (JEOL) на уровне штриховой линии рис. 3, $a$. Рис. $3, b$ отражает состояние поверхности после внедрения КС, образовавшейся при схлопывании воронки с углом $45^{\circ}$. Видны затвердевшие подтеки размером более $100 \mu \mathrm{m}$ и отдельные капли алюминия размером 5-10 $\mu \mathrm{m}$. При увеличении проявляется структура поверхностного слоя каверны с трещинами. Состояние поверхности каверны после внедрения алюминиевой струи со скоростью более $10 \mathrm{~km} / \mathrm{s}$ существенно меняется. При микронном разрешении проявляются многочисленные наносферы размером 20-100 nm (рис. 3,c). Наносферы образуют кластеры размером $0.2-0.5 \mu \mathrm{m}$ с порами в центре из-за 

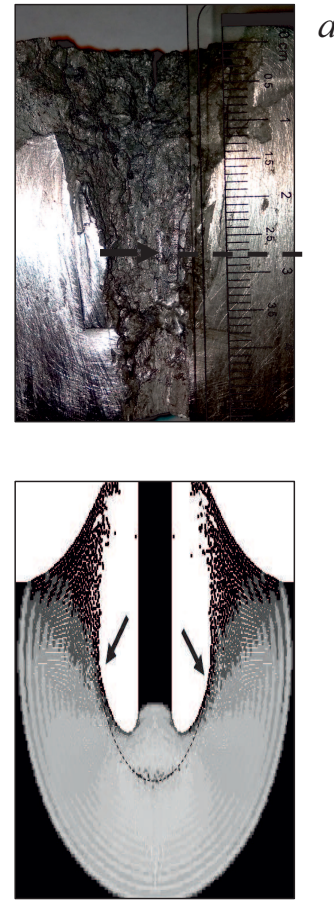

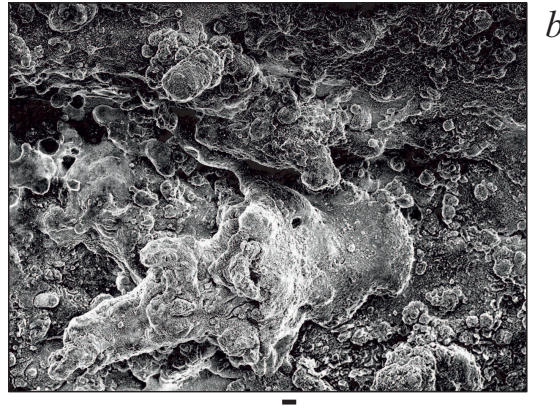

$10 \overline{\mu m}$

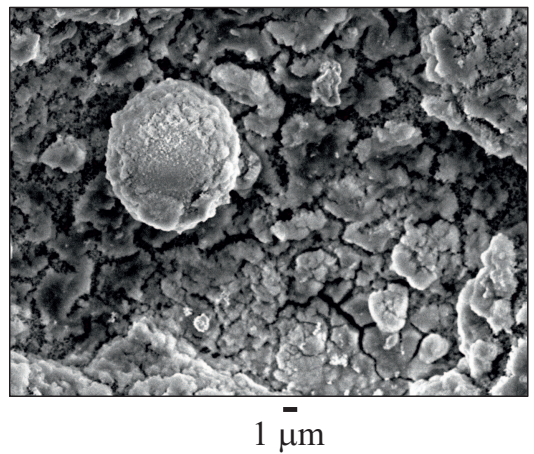

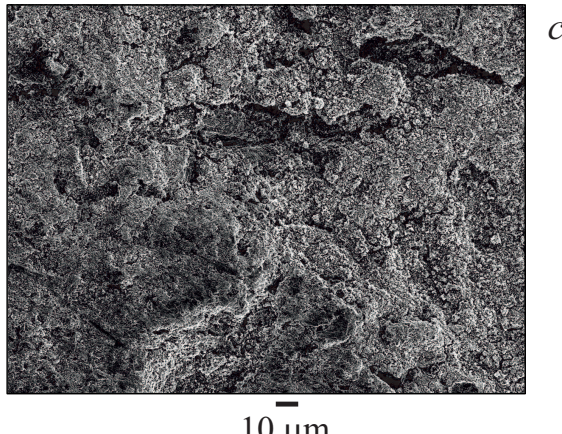

$10 \bar{\mu} \mathrm{m}$

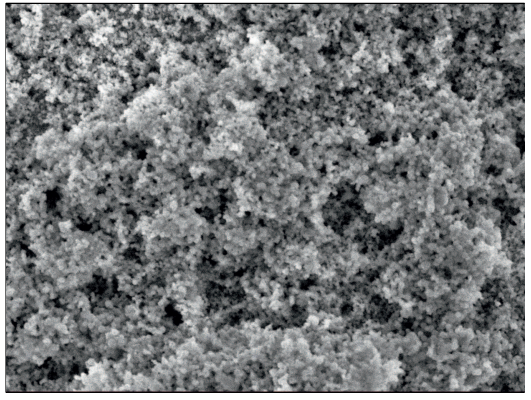

$\overline{1 \mu \mathrm{m}}$

Рис. 3. SEM-изображения каверны в АМГ6 после действия алюминиевой струи. $a-$ общий вид каверны и области внедрения, штриховая линия - глубина регистрации поверхности каверны $\sim 1 \mathrm{~cm}$, стрелки указывают поверхность генерации наносфер; $b-$ поверхность каверны, образованной струей из воронки с углом $45^{\circ} ; c-$ поверхность каверны, образованной струей из воронки с углом $20^{\circ}$.

неплотной упаковки. Поверхностный слой имеет вид пористой массы. Распределение наносфер по размерам аналогично имеющему место для порошков, получаемых при электрическом взрывании проводников [12].

В рассматриваемом процессе наносферы появляются при разгрузке свободной поверхности в области внедрения (стрелки на рис. 3,a) растекающегося отрезка струи, сжатого отраженной от границы раздела с преградой ударной волной. Существенно, что кинетическая энергия, вносимая потоком со скоростью более $9 \mathrm{~km} / \mathrm{s}$, в несколько раз превышает удельную теплоту испарения алюминия. С учетом перехода в отраженную ударную волну и доли тепловой энергии в ней энергии для преобразования значительной части потока в наносферы достаточно. Из рис. 3, $c$ видно, что разгрузка струи в зоне внедрения при скоростях более $9 \mathrm{~km} / \mathrm{s}$ идет с образованием пористой массы наносфер. Радиальное взаимодействие расширяющегося материала с вновь поступающим потоком струи является причиной внутренней дестабилизации высокоскоростного внедрения. Преодоление схлопывающегося материала приводит к временной приостановке на $\sim 1 \mu$ s внедрения на глубине 30-35 mm (стрелка на рис. 2), после чего остаток удлиненного ударника интенсивно расходуется на стенках каверны в преграде. Недостаток экспериментальных результатов и неопределенность в описании процессов расширения материала струи в области разгрузки не позволяют определить время задержки радиального воздействия [11].

Совокупность данных (состояние ,замороженной“ поверхности каверны, изменения в траектории внедрения, тождественность наблюдаемых особенностей внедрения фазовому состоянию) позволяет предположить влияние плавления алюминия на дестабилизацию внедрения струи при скоростях более $9 \mathrm{~km} / \mathrm{s}$.

Исследованный диапазон скоростей алюминиевых струй и их действие по преграде из алюминиевых сплавов служат исходной базой для оценки последствий воздействия техногенного мусора на космические объекты. Естественная дестабилизация внедрения удлиненного ударника при достижении параметров фазовых превращений в алюминии увеличивает эффективность экранной защиты и должна учитываться при оценке рисков поражения.

\section{Финансирование работы}

Работа выполнена при финансовой поддержке Российского фонда фундаментальных исследований в рамках научного проекта № 18-08-00487/18.

\section{Конфликт интересов}

Авторы заявляют, что у них нет конфликта интересов. 


\section{Список литературы}

[1] IADC-04-03 v. 7. Protection manual. 2014. 288 p.

[2] Christiansen E.L. Meteoroid/debris shielding. TP-2003210788. Houston: NASA Johnson Space Center, 2003. P. 114.

[3] Rumiantsev B.V., Mikhaylin A.I. // Acta Astron. 2017. V. 135. P. 15-20. https://doi.org/10.1016/j.actaastro.2016.11.002

[4] Козачук А.И., Михайлин А.И., Павлов С.И., Румянцев Б.В., Сильников М.В. // Письма в ЖТФ. 2019. Т. 45. B. 5. C. 13-16. DOI: 10.21883/PJTF.2019.05.47389.17578

[5] Физика взрыва / Под ред. Л.П. Орленко. Изд. 3-е, перераб. М.: Физматлит, 2002. Т. 2. 832 c.

[6] Rumiantsev B.V., Guk I.V., Kozachuk A.I., Mikhailin A.I., Pavlov S.I., Sil'nikov M.V. // Acta Astron. 2019. V. 163. Part A. P. 73-78. https://doi.org/10.1016/j.actaastro.2019.03.065

[7] Katayama M., Takeba A., Toda S., Kibe S. Numerical simulation of jet formation by shaped charge and its penetration into bumpered target // Proc. of the 2nd Eur. Conf. on space debris. 1997. V. 393. P. 411-416.

[8] http://www.ihed.ras.ru/rusbank/ [Электронный pecypc].

[9] Минаков Д.В. Расчет термодинамических свойств плотной плазмы металлов методом функционала плотности и квантовой молекулярной динамики. Канд. дис. М.: Объединенный институт высоких температур РАН, 2015. 127 с.

[10] Khishchenko K.V. // J. Phys.: Conf. Ser. 2008. V. 98. P. 032023.

[11] Румянцев Б.В. // ЖТФ. 2019. Т. 89. В. 5. С. 685-691. DOI: $10.21883 /$ JTF.2019.05.47469.337-18

[12] Назаренко О.Б. Электровзрывные порошки: получение, свойства, применение / Под ред. А.П. Ильина. Томск: Изд-во ТПУ, 2005. $148 \mathrm{c.}$ 